\title{
Activismo artístico como nueva herramienta sindical de jóvenes trabajadores precarizados en Argentina*
}

\author{
Marina Adamini*
}

Recibido: 21 de diciembre de 2017

Evaluado: 30 de enero 2018

Aceptado: 16 de abril de 2018

\section{RESUMEN}

Desde las ciencias sociales del trabajo, resulta un consenso señalar que el avance de la precarización laboral genera un desafío para las organizaciones sindicales tradicionales, por la segmentación que genera en la clase trabajadora, en relación a sus condiciones y demandas de trabajo y por la dificultad de representar a aquellos trabajadores que se encuentran trabajando en condiciones no registradas e informales. En este marco, nuestro trabajo se propone reflexionar sobre las nuevas formas de acción colectiva que establecen los jóvenes trabajadores precarizados, frente a estas limitaciones del sindicalismo tradicional para canalizar sus luchas. Nuestra hipótesis de trabajo es que, ante la falta de acceso a la representación sindical tradicional y a sus mecanismos formales de negociación y de lucha, los precarizados recurren a repertorios de acción alternativos para dar visibilidad a sus luchas e instalar en la arena política sus demandas. Uno de estos repertorios es el activismo artístico, que consiste en la utilización de imágenes, canciones y actuaciones como canal de denuncia y protesta sobre sus problemáticas laborales. Es sobre este repertorio de acción no convencional en el mundo del trabajo donde centramos nuestro análisis, el cual ganó un gran lugar en las recientes movilizaciones de jóvenes precarizados en Argentina. En

Artículo de investigación. Este artículo fue elaborado en el marco del plan de investigación de la autora, titulado: "Memorias político-sindicales en las identificaciones colectivas del presente. Un análisis a partir de los discursos de organizaciones de jóvenes trabajadores precarizados en la Argentina de la posconvertibilidad", dirigido por la Dra. Mariana Busso y el Dr. Ricardo Pasolini y subsidiado por el Consejo Nacional de Investigaciones Científicas y Tecnológicas (Conicet) (DOI: https://orcid.org/0000-0002-3571-5570). DOI: http://dx.doi. org/10.15332/ s1794-3841.2018.0029.06

** Doctora en Ciencias Sociales, de la Universidad Nacional del Centro de la Provincia de Buenos Aires (Unicen). Investigadora asistente en el Conicet con sede en el Instituto de Geografía, Historia y Ciencias Sociales (IGEHCS). Correo electrónico: marina.adamini@gmail.com. Dirección postal: Pinto 348. Tandil, Argentina (7000). 
términos metodológicos cualitativos, realizamos un estudio de caso cualitativo sobre tres organizaciones de jóvenes precarizados argentinos que aplicaron el activismo artístico en sus jornadas de protesta, en el período 2005-2015, buscando comprender su emergencia como nuevo repertorio gremial.

Palabras clave: precarización laboral, activismo artístico, jóvenes trabajadores, repertorios de acción colectiva, sindicalismo, Argentina. 


\section{Artistic activism as a new trade union tool of young precarious workers in Argentina}

Received: December 21, 2017

Evaluated: January 30,2018

Accepted: April 16, 2018

\section{Abstract}

From the social sciences of the labor, it is a consensus to point out that the advance of work precariousness generates a challenge for the traditional trade union organizations, because of the segmentation it generates in the working class, in relation to their conditions and job demands, and for the difficulty in representing those workers who are working in unregistered and informal conditions. In this context, this paper aims to reflect on the new forms of collective action that young precarious workers establish in response to these limitations of traditional trade unionism to channel their struggles. Our hypothesis is that in the absence of access to traditional trade union representation and its formal mechanisms of negotiation and struggle, the precarious workers turn to alternative repertoires of action to give visibility to their struggles and install their demands in the political ground. One of these repertoires is artistic activism, which consists in the use of images, songs and performances as a channel for denouncing and protesting about their labor problems. It is on this unconventional trade union repertoire where we focus our reflection in this paper, which gain a great place in the recent mobilizations of young precarious people in Argentina. In qualitative methodological terms, we conducted a qualitative and comparative case study on three Argentinian organizations of young precarious workers who resorted to artistic activism in their protests, during the period 2005-2015, seeking to understand its emergence as a new trade union repertoire.

Keywords: work precariousness, artistic activism, young workers, repertoires of collective action, trade unionism, Argentina. 


\section{Ativismo artístico como nova ferramenta sindical para jovens trabalhadores precários na Argentina}

\section{RESUMO}

Desde as ciencias sociais do trabalho, é um consenso assinalar que o progresso da insegurança no emprego cria um desafio para os sindicatos tradicionais, pela segmentação gerado na classe trabalhadora em relação às suas condições e exigências do trabalho e da dificuldade em representar os trabalhadores que estão trabalhando em condições não registradas e informais. Nesse contexto, nosso trabalho pretende refletir sobre as novas formas de ação coletiva que os jovens trabalhadores precários, estabelecem diante dessas limitações do sindicalismo tradicional para canalizar suas lutas. Nossa hipótese de trabalho é que, a falta de acesso a representação sindical tradicional e mecanismos formais de negociação e luta, o resort precária para repertórios de ação alternativa para dar visibilidade às suas lutas e instalar na arena política suas demandas. Um desses repertórios é o ativismo artístico, que consiste no uso de imagens, canções e performances como um canal de denúncia e protesto sobre seus problemas de trabalho. É sobre esse repertório de ação não convencional no mundo do trabalho que enfocamos nossa análise, que ganhou um ótimo lugar nas recentes mobilizações de jovens precários na Argentina. Em termos metodológicos qualitativos, foi realizado um estudo de caso qualitativo das três organizações de jovens argentinos que aplicaram ativismo artístico precária em seus dias de protesto, no período de 2005-2015, procurando compreender o seu surgimento como um novo repertório gremial.

Palavras-chave: insegurança no trabalho, ativismo artístico, jovens trabalhadores, repertórios de ação coletiva, sindicalismo, Argentina.
Recebido: 21 de dezembro de 2017

Abaliado: 30 de janeiro de 2018

Aceito: 16 de abril de 2018 


\section{INTRODUCCIÓN}

Las transformaciones ocurridas en el mundo del trabajo a partir de la implementación de la ofensiva neoliberal en los años setenta, han sido objeto de reflexión desde diferentes enfoques en las ciencias sociales. Sus principales ejes de análisis giran en torno a la pérdida de centralidad del trabajo asalariado, estable y protegido y el avance de nuevas formas laborales inestables y flexibles, ligadas al continuo proceso de precarización del trabajo en el marco de una nueva sociedad posindustrial. Desde una perspectiva crítica, algunos autores de la sociología del trabajo (Dubar, 2000; Bauman, 2005; Sennett, 2000), han advertido sobre los efectos negativos que estas transformaciones tienen sobre las identidades y organizaciones colectivas de los trabajadores, las cuales pierden soportes estables y compartidos sobre los cuáles definirse ante el continuo proceso de segmentación laboral. Así, este diagnóstico sobre la crisis de las identidades laborales va acompañado por el de la crisis del sindicalismo, en donde la baja en la tasa de sindicalización es utilizada como reflejo de este proceso de reflujo.

Desde otra postura, autores como De la Garza (2010) y Antunes (1999) advierten que, si bien el proceso de precarización laboral afecta las formas de identificación y organización tradicional de los trabajadores, esto no implica el fin del sindicalismo sino su transformación. En este sentido, rescatan cómo ante el avance de la precarización y segmentación del trabajo, surgen nuevas formas de organización y acción colectiva que buscan representar las diferentes demandas de los trabajadores precarios por canales informales, a partir de la autoorganización y el uso de repertorios de lucha no tradicionales. Un rasgo compartido de estas nuevas formas de organización y acción colectiva es el carácter no institucionalizado de las mismas, que se produce por el propio carácter precario de los trabajadores.

En este artículo, focalizamos la mirada en el análisis de la renovación en los repertorios de acción sindical, a través del estudio del activismo artístico como nueva herramienta de lucha de jóvenes trabajadores precarizados en Argentina. A través de un abordaje comparativo, seleccionamos como casos de estudio tres organizaciones de jóvenes trabajadores precarizados que han desplegado el activismo artístico en sus protestas en el período 2005-2015. Se trata de la Coordinadora de Trabajadores Precarizados (CTP) y Jóvenes Científicos Precarizados (JCP), ambas de la ciudad de Buenos Aires, y La Fragua, de la ciudad de La Plata. A través de su estudio comparativo, buscamos analizar cómo incide su condición laboral precaria en el uso del activismo artístico como repertorio de acción sindical. La hipótesis que orienta este trabajo es que ante la falta de acceso a las formas de representación sindical tradicionales, los precarizados recurren a canales alternativos de protesta, como el activismo artístico, buscando dotar de visibilidad a sus demandas y obtener así respuestas institucionales.

\section{Principios metodológicos}

En términos metodológicos, nuestra investigación adopta una perspectiva eminentemente cualitativa, como forma de acceso al universo de significación de los sujetos (Vasilachis de Gialdino, 2008). Dentro de ella, nos enmarcamos en un posicionamiento 
estructural-constructivista (Bourdieu, 1998), que implica la comprensión del universo de sentidos de los actores de un modo contextuado, tomando en consideración el carácter estructurado y estructurante de lo simbólico a la luz de su contexto de acción.

A partir de estos principios metodológicos cualitativos y estructural-constructivista, realizamos un estudio de caso comparativo, a partir de la selección de tres organizaciones de jóvenes precarizados de las ciudades de Buenos Aires y La Plata (Argentina), en el período 2005-2015: CTP, JCP y La Fragua. La elección de estos casos de estudio no responde a sus particularidades, sino a sus rasgos compartidos -en tanto autoorganizaciones sindicales de jóvenes trabajadores precarizados-, que nos permite reflexionar sobre una problemática más profunda, que las atraviesa, referida a la transformación en las formas de acción colectiva de los trabajadores. Por ese motivo, hablamos de un estudio de caso instrumental (Stake, 1994) en términos teóricos, donde la selección de los casos implica un recorte empírico del mundo social a partir de los cuales buscamos reflexionar en torno a una problemática teórica de carácter más general.

En el marco de esta perspectiva, las técnicas cualitativas de relevancia de datos fueron utilizadas en las entrevistas en profundidad y el abordaje documental de panfletos, carteles y fotografías (en el entorno de momentos de protesta social de las organizaciones en estudio). Las entrevistas fueron realizadas, en las tres organizaciones en estudio, durante los años 2014 y 2015, y sus ejes estuvieron atravesados por las demandas laborales, formas de organización, repertorios de acción y vinculación con los sindicatos tradicionales. A través del relato de los jóvenes trabajadores precarizados, observamos los sentidos atribuidos a sus repertorios de acción colectiva, fundamentalmente al activismo artístico. Aplicamos en su abordaje la estrategia de análisis del discurso, desde la teoría de Benveniste (1974), que permite acceder a los posicionamientos subjetivos de los actores a partir de las marcas enunciativas presentes en sus relatos.

Por otro lado, la relevancia documental de publicaciones panfletarias y fotografías de las protestas de las organizaciones, fue utilizada como recursos de contextualización de los discursos de los sujetos entrevistados. En el caso de los panfletos, estos constituyen una fuente de acceso al discurso colectivo de la organización en tanto "nosotros", permitiendo acceder a la identificación de sus demandas, otredades y repertorios de acción. Entre tanto, las fotografías de las protestas, a las cuales accedimos a partir de las páginas virtuales de las organizaciones y de fuentes periodísticas de registro, nos permitieron observar el campo de territorialización (Giménez, 1996) de sus acciones colectivas, identificando el lugar de la protesta, la disposición espacial de los repertorios de acción, los participantes y los insumos utilizados en el desarrollo de estas. El estudio de los documentos y fotografías se realizó a partir del análisis de contenido, permitiendo evaluar comparativamente sus elementos constitutivos a partir de su recurrencia y alternancia.

\section{Precarización de los TRABAJADORES Y DE SUS FORMAS DE ACCIÓN COLECTIVA}

Desde las ciencias sociales del trabajo, se marca un momento de quiebre en las 
relaciones laborales a partir de la crisis de acumulación capitalista acontecida a mediados de los años setenta, que obtuvo como una de sus respuestas la transformación de las relaciones de producción a partir de la expansión global de un nuevo modelo laboral flexible (en reemplazo del modelo salarial fordista $)^{1}$. De esta manera, el mundo del trabajo estable y protegido, con una clase obrera homogénea y de carácter predominantemente industrial que caracterizó a los 30 gloriosos años de la posguerra, dio lugar a un nuevo entramado de relaciones laborales, que tienen como rasgo característico el carácter inestable y precario de las empleos, la segmentación de la clase trabajadora en relación a sus condiciones contractuales y materiales de trabajo y la creación de nuevas formas productivas ligadas a la expansión del sector servicios, las nuevas tecnologías y la valorización financiera (Boyer, 1978; Antunes, 1999).

Este proceso de transformación laboral, ganó espacio en el campo académico como objeto de reflexión a partir de su consolidación en los años noventa. Desde un posicionamiento crítico, surgieron así las llamadas teorías del fin del trabajo (Gorz, 1997; Rifkin, 1996; Offe, 1985), que pregonaron la desaparición del trabajo como fuente de identificación social y organización colectiva ante el avance del desempleo estructural, la retracción del sector industrial, las nuevas tecnologías y la robotización del proceso productivo, entre otros factores. Dentro de esta perspectiva, otro conjunto de teorías (Silver, 2005; Visser, 1991) señalaban que

1 Producción en serie. El "fordismo" como modelo de producción, resulta rentable siempre que el producto pueda venderse a un precio relativamente bajo en relación a los salarios promedio, generalmente en una economía desarrollada. las transformaciones del mundo del trabajo, ante el avance de la precarización y segmentación laboral, estaban conduciendo a una crisis del sindicalismo, evidenciada en la disminución de la tasa de afiliación sindical.

Por su parte, en América Latina, De la Garza (2010) y Antunes (1999), analizaban las transformaciones del mundo laboral a partir de sus impactos ofensivos, pero también, de las formas de resistencia desplegadas por los trabajadores frente a ellos. Así, sin negar el proceso de heterogeneización del mundo del trabajo y su impacto regresivo sobre el sindicalismo tradicional, estos autores destacaban las nuevas formas de organización de los trabajadores que emergían como reacción ante las dificultades de representación del sindicalismo tradicional. Mostraban así, la emergencia de sindicalismos alternativos que ampliaban sus bases e incorporaban diferentes tipos de trabajadores como los precarizados, desocupados e informales.

En el mundo anglosajón, estas nuevas formas de sindicalismo son analizadas por diferentes autores a partir del concepto de: "sindicalismo de movimiento social" (Seidman, 1994; Moody, 1997; Mazur, 2000). Este nuevo sindicalismo emerge ante la crisis de representación y la baja en la tasa sindical, buscando ampliar las bases del sindicalismo tradicional, incorporando no solo a aquellos trabajadores precarios e informales (que se encuentran excluidos de la posibilidad de afiliación sindical formal), sino también, estableciendo vínculos con organizaciones sociales y culturales, por fuera del mundo del trabajo. Se diferencia además, del sindicalismo tradicional, por posicionarse como de carácter (más) democrático, pluralista y 
dispuesto a trabajar con movimientos sociales en el territorio donde reside la clase trabajadora, ampliando sus demandas más allá del mundo laboral e incorporando nuevas herramientas de lucha.

Pero más allá de este debate teórico entre las teorías que anunciaban el fin del sindicalismo o su mutación, en términos empíricos observamos que en Argentina, durante el período 2005-2015, se dio un proceso de recuperación laboral acompañado por la revitalización del sindicalismo tradicional (Senén y Haidar, 2009; Etchemendy y Collier, 2008). Luego de una década atravesada por la inmovilidad de los sindicatos ante la ofensiva del desempleo -que quitó poder de lucha y de organización a los trabajadores-, en la década del dos mil se presentó un proceso conjunto de recomposición laboral y sindical. Este proceso de reactivación del sindicalismo se dio como parte del proceso de reinstalación del orden institucional durante el Gobierno de Néstor Kirchner (20032007), en un marco de crecimiento económico y de recuperación laboral.

En términos cuantitativos, son los sindicatos tradicionales quienes ocuparon un rol central en este proceso de revitalización sindical por su presencia en la escena pública, ante el crecimiento de las tasas de afiliación sindical y de las negociaciones colectivas. A pesar de ello, Senén González y Del Bono (2013) advierten sobre la heterogeneidad cualitativa de este proceso, marcando también la presencia de un sindicalismo de base, que con nuevas formas de organización y de acción colectiva, irrumpe en el escenario de la conflictividad laboral. Al respecto, dan cuenta de esta heterogeneidad clasificando la revitalización sindical argentina bajo formas descendente, ascendente y periférica. La revitalización descendente refiere a la producida bajo la estructura tradicional vertical del sindicato de arriba hacia abajo: de la cúpula a las bases, a través de negociaciones y acuerdos; la revitalización ascendente, en cambio, revierte la estructura vertical tradicional sindical viéndose movilizada por las bases, frente a sus dirigencias, como comisiones internas o cuerpos de delegados, a través de diferentes conflictos; por último, la revitalización periférica alude a aquellas experiencias que se dan en los márgenes de la estructura sindical tradicional, a través del desarrollo de agrupaciones y colectivos de trabajadores de base, presentando como caso paradigmático los trabajadores de los call centers.

Es en las modalidades ascendentes y periféricas, donde se dio la mayor presencia de jóvenes trabajadores precarizados como nuevos militantes sindicales, quienes con prácticas horizontales y autónomas, disputaban la orientación de los conflictos laborales, desarrollando nuevas modalidades de protesta que apelaban a ganar visibilidad pública. Al respecto, Varela (2009) explica la emergencia de este sindicalismo de base juvenil, a partir de la contradicción entre un contexto laboral revitalizado -que amplía el horizonte de aspiraciones laborales-, y la ausencia de espacios institucionales para que los precarizados lleven a cabo sus luchas, conduciéndolos a desarrollar sus propias organizaciones sindicales por debajo y por fuera de los canales sindicales tradicionales.

Svampa (2010) habla en este sentido de prácticas renovadoras en el repertorio de acción sindical y política por parte de una nueva generación militante, ligada al uso 
del activismo artístico en las protestas y vinculadas con movimientos sociales y culturales. La autora establece una conexión entre estas militancias juveniles del período kirchnerista con las prácticas políticas horizontales y asamblearias expandidas en la Argentina durante el estallido social ocurrido en diciembre de $2001^{2}$, donde emergieron múltiples organizaciones de base de carácter autonomista, que cuestionaban las formas tradicionales de organización, representación y acción colectiva.

Surgían así nuevas camadas de jóvenes delegados sindicales que, luego de tantos años de aparente inmovilidad y descreimiento en las organizaciones sindicales, habían revalorizado la acción gremial como herramienta de lucha. Eran en gran parte tributarios de ese ethos libertario, partidario de la acción radical, más proclive tanto a las alianzas con las izquierdas como al repudio a las estructuras burocráticas y empresariales (Svampa, 2010, p. 22).

En otros trabajos (Adamini, 2015 y 2016), conceptualizamos a estas nuevas agrupaciones gremiales como "organizaciones sindicales informales". Nos referimos con ello a aquellas agrupaciones de base conformadas por jóvenes trabajadores que, desprovistos del derecho a la afiliación sindical formal

2 Esta crisis se dio en un marco de deslegitimación del consenso neoliberal, luego de una década de aplicación de sus políticas que debilitaron las estructuras de integración social y ocasionaron un crecimiento exponencial de la pobreza y el desempleo en Argentina. Las ineficientes respuestas a la crisis económica del por entonces Gobierno de Fernando De la Rua, con sucesivos ajustes, multiplicación de las monedas en circulación, cesación de pago y recorte del gasto público, socavó la legitimidad del propio orden político desencadenando un proceso de alzamiento popular, que condujo a su renuncia y profundizó el clima de deslegitimación institucional del orden político. por su condición contractual precaria, desarrollan formas alternativas de organización gremial como agrupaciones, movimientos, coordinadoras, frentes y asociaciones de trabajadores precarizados. Se trata de agrupaciones gremiales que no asumen la forma de sindicato, es decir, que no se encuentran inscritas jurídicamente ni cuentan con un régimen formal de representación, estatutos ni cotización de sus afilados. En este trabajo, buscamos profundizar su caracterización, abordando el uso que ellas realizan del arte como herramienta de protesta en sus movilizaciones contra la precarización laboral.

\section{De Qué hablamos CuANDo SE MENCIONA EL ARTE COMO HERRAMIENTA DE PROTESTA}

Antes de continuar con el análisis del activismo artístico como repertorio de protesta de los jóvenes precarizados en Argentina, consideramos necesario explicitar a qué nos referimos cuando hablamos de este repertorio (atípico) en el mundo gremial. Vemos así, que el uso del arte como herramienta de protesta política ha sido descrito a partir de diferentes conceptos como los de "activismo artístico", "activismo cultural", "artivismo", "arte activista" o "arte contextual", entre otros. En este trabajo utilizamos el concepto de "activismo artístico", por el lugar central que otorga al carácter político del arte. En las otras definiciones, hay en cambio un mayor énfasis del carácter artístico de la acción política. En cierta manera, el debate teórico entre ellas reside en el cuestionamiento a la efectividad del arte como herramienta política ${ }^{3}$. Mientras la

3 Delgado (2013) sostiene que el artivismo actual "a diferencia de las viejas creaciones artísticas al servicio de la agitación y propaganda 
primera perspectiva piensa al arte desde su carácter de herramienta política, la última lo piensa como una "mera estetización de la acción directa" (Delgado, 2013, p. 73).

Fue el dadaísmo alemán de principios de siglo XX el que acuñó la categoría de "activismo artístico", para referir a la articulación entre prácticas estéticas y políticas. La misma fue recuperada por la vanguardia europea posmoderna de los sesenta, con su intencionalidad de provocación, extendiendo el arte al espacio público con las performances y los happenings. Pero, ¿de qué hablamos cuando se menciona el "activismo artístico"? Al respecto, Longoni (2009) recupera para su definición la propuesta originalmente creada por el dadaísmo, definiendo al activismo artístico como las "producciones y acciones, muchas veces colectivas, que abrevan en recursos artísticos con la voluntad de tomar posición e incidir de alguna forma en el territorio de lo político" (p. 1).

El arte en su forma activista, se opone así a su concepción moderna como esfera autónoma, individual y espiritual, cuyo espacio de difusión se resguarda en museos y espacios cerrados específicos para su exposición. El activismo artístico implica un arte abierto, que se despliega en espacios públicos, generando desconcierto y sorpresa por

política y de clase, el arte activista, en nombre de una pretendida adaptación a las condiciones impuestas por la nueva etapa posfordista del capitalismo, abdica de cualquier principio de encuadre ya no organizativo sino ni siquiera ideológico y se entrega al servicio de la agenda de movimientos sociales circunstanciales, reclamando una fantástica democracia real de la que un mítico espacio público debería ser materialización. De hecho, los últimos grandes movimientos civiles que han conocido algunos países industrializados y que postulan la democracia como antídoto al capitalismo -15M en España, \#YoSoy132 en México, MANE chileno u Occupy Wall Street en Estados Unidos- no son sino la apoteosis de esta festivalización generalizada de la protesta que el arte activista presagiaba" (p. 76) el carácter inesperado de su intervención y la descontextualización de los elementos cotidianos del espacio que genera. A diferencia del arte moderno, que planteaba una relación binaria entre artista y espectadores, el activismo artístico se propone como una producción dialógica, procesual, colaborativa e igualitaria (Almazán y Clavo, 2007; Felshin, 2001; Pérez Balbi, 2014). Si bien en sus producciones existe un artista individual o colectivo que es quien crea o despliega las intervenciones, se desdibuja en el propio desarrollo de la acción.

Respecto a las herramientas del activismo artístico, Longoni (2009) señala que sus prácticas adoptan formatos convencionales (cuadros, imágenes, actuaciones) insertos en espacios no habituales para el arte, con intervenciones gráficas urbanas (en paredes, calles, afiches, vestimentas, distintivos) y propuestas experimentales vinculadas al arte de acción (performances, happenings). Por lo general, las intervenciones se dan en espacios públicos y suelen ser temporales, y el desafío consiste en dar la mayor visibilidad a las prácticas para provocar interpelaciones en quienes se cruzan con ellas.

La vocación de denunciar, visibilizar y propiciar la reflexión es explícita y la estrategia más frecuente para lograrlo es la resignificación de objetos, frases y espacios públicos, la desfuncionalización de elementos y discursos, la irrupción y descontextualización de palabras e imágenes, el humor y la ironía (Bruno, 2012, p. 5).

En Argentina, la mayor expansión del “activismo artístico" como herramienta de lucha, se dio a fines de los noventa y principios de la primera década del presente siglo, en 
vinculación con el clima de emergencia de nuevos movimientos sociales y ante el fortalecimiento de una retórica autonomista en la organización popular con formas de organización horizontales y asamblearias. Pero si nos sumergimos en su genealogía histórica, el primer antecedente se dio en el país con la intervención "Tucumán Arde" en 1968, realizada en las sedes del sindicato CGTA de los Argentinos de Rosario y Buenos Aires. El objetivo de esta intervención era denunciar la explotación laboral en los ingenios azucareros tucumanos, a través de una muestra que incluía filmaciones, fotografías y recursos estéticos novedosos, como carteles en el suelo con los nombres de los dueños de los ingenios, que cada asistente debía necesariamente pisar para ingresar a la muestra.

Un segundo antecede nacional de activismo artístico fue "El Siluetazo" de 1983, realizado en el proceso de finalización de la dictadura militar. Este consistió en una intervención colectiva en las calles de Buenos Aires con dibujos de miles de siluetas humanas en veredas, persianas y paredes, en alusión a los desaparecidos, víctimas de la dictadura. Esta intervención fue realizada por artistas, docentes y estudiantes universitarios, iniciándose en la emblemática Plaza de Mayo y extendiéndose por toda la ciudad, con una repercusión pública (Pérez Balbi, 2012).

Pero, más allá de estos antecedentes, fue a fines de los noventa y fundamentalmente en el marco del proceso de agitación social del 2001, cuando se produjo en Argentina la expansión del activismo artístico como herramienta de lucha de diferentes movimientos sociales (derechos humanos, feministas, estudiantes, asambleas barriales) e incluso se dio la emergencia de múltiples colectivos de activistas culturales.

Longoni (2009) identifica dos coyunturas cruciales que resultaron fértiles para la emergencia de grupos de activismo artístico: en primer lugar, la aparición de H.I.J.O.S. ${ }^{4}$ en 1995, con el empleo del "escrache ${ }^{\prime \prime}$ como herramienta de protesta; y en segundo lugar, el clima de inestabilidad institucional y agitación callejera vivenciado en la crisis del 2001. Respecto a la primera coyuntura, en un marco de consolidación del modelo neoliberal y de aprobación de leyes de impunidad respecto a los represores de la última dictadura militar, emergieron grupos de artistas como "GAC" y "Etcétera..." que promovían acciones de intervención artística en el espacio público y se involucraron con los escraches realizados por H.I.J.O.S. Con la ausencia de condena legal ante los responsables del genocidio de la última dictadura, el escrache apuntaba a una condena social visibilizando a los represores y sus acciones a partir de intervenciones estéticas novedosas como mapas, pinturas, música, muñecos, máscaras y disfraces.

La segunda coyuntura refiere al período abierto por la crisis social, política y económica del 2001, en un marco de cuestionamiento a los actores políticos tradicionales, en el que surgieron grupos de activistas artísticos como Taller Popular de Serigrafía, Argentina Arde y Arde! Arte, entre otros, que se articulan con los nuevos actores

4 Organización de derechos humanos constituida por hijos de desaparecidos víctimas de la última dictadura militar en Argentina (1976-1983)

5 Escrache es el nombre dado en Argentina, Uruguay y España a un tipo de manifestación en la que un grupo de activistas de derechos humanos se dirige al domicilio o lugar de trabajo de alguien a quien se quiere denunciar. 
políticos de movilización social como las asambleas populares, los piquetes $^{6}$ y las fábricas recuperadas, participando en sus movilizaciones y apoyando en el despliegue de recursos culturales para dar visibilidad a sus demandas. En estos espacios se dio una articulación de herramientas estéticas con recursos de otros campos, como la fotografía, el cine, los documentales, el periodismo alternativo y la educación popular (Svampa, 2010). Así, en un clima de efervescencia política autonomista y asamblearia, muchos activistas artísticos terminaron participando como militantes de estos nuevos movimientos sociales populares.

Luego de la crisis del 2001, con la reinstalación del orden institucional bajo el Gobierno de Néstor Kirchner (2003-2007), en un clima de recuperación económica y estabilización política, se produjo una paulatina desintegración de las autoorganizaciones surgidas al calor de la crisis y con ello, de los grupos de activismo artístico (Longoni, 2009; Pérez Balbi, 2014). Desde el propio Estado, se dispuso una política activa de derechos humanos y se integró dentro de las esferas del Gobierno a militantes de diferentes organizaciones sociales y culturales, quienes encontraron en la arena política otro canal para vehiculizar sus demandas. Sin embargo, a pesar de este reflujo de los grupos de activismo artístico, observamos que los recursos artísticos perduran como herramientas de lucha en las manifestaciones de trabajadores, estudiantes, partidos políticos y otros movimientos sociales.

En sintonía con ello, Longoni (2009) sostiene que en la actualidad no hay protesta social

6 Piquete es una forma de protesta donde un grupo de personas, dentro del contexto de una huelga, intenta que esta sea secundada. que no recurra a dispositivos visuales. La provocación subjetiva es considera como condición para dar visibilidad a las manifestaciones, atraer a los medios de comunicación para que vuelvan público al grupo y sus demandas, y obtener consenso social respecto a estas. Esto se da incluso en el caso de actores tradicionales -como sindicatos y partidos- que cuentan con canales institucionales para vehiculizar sus demandas.

Quizás la mayor señal de la vigencia del "activismo artístico", hoy puede notarse en hasta qué punto se ha incorporado la "dimensión creativa" en las distintas formas de la protesta social, además de la notable profusión anónima y hasta espontánea de recursos gráficos (esténciles, carteles, intervenciones sobre publicidad, etc.) que es habitual encontrar por todas partes (p. 5).

\section{"ACtivismo ARtístico" COMO REPERTORIO DE ACCIÓN DE JÓVENES TRABAJADORES PRECARIZADOS EN LA REVITALIZACIÓN SINDICAL ARGENTINA (2005-2015)}

Diferentes autores de las ciencias sociales del trabajo (Abal Medina, 2014; Varela, 2009) destacan el rol de los jóvenes trabajadores como actores activos del proceso de revitalización sindical argentino (20052015), refiriéndose a ellos como una "nueva generación militante". Pensar en una generación implica, en términos de Mannheim (1928), referirse a actores que comparten además de su contemporaneidad como jóvenes, un mismo clima de época; el cual está conformado por nuevas condiciones materiales y simbólicas que los generan en tanto 
grupo, hitos que los marcan como nuevo grupo social contemporáneo. En este sentido, el autor sostiene que los jóvenes que experimentan los mismos problemas históricos concretos forman parte de la misma generación.

En el caso de la nueva generación militante que participó del proceso de revitalización sindical en Argentina durante el período 2005-2015, el hito histórico que los atravesó generacionalmente fue la crisis del 2001. Más allá de su participación directa en las manifestaciones populares de ese período, estas formaron parte del clima de época en que atravesaron su socialización juvenil, volviéndose un dispensario sobre nuevas formas de organización (autónomas y horizontales) y de repertorios de acción (con acción directa y recursos novedosos como el activismo artístico) que eran aprehendidos y naturalizados por ellos. Muchos de estos elementos novedosos de organización y de lucha, fueron aplicados por ellos al momento de realizar sus primeras experiencias de militancia como trabajadores durante el período kirchnerista, en el marco del sindicalismo de base.

Es sobre las acciones colectivas de esta nueva generación sindical militante, donde focalizamos la mirada en nuestra investigación, observando el rol que juega el activismo artístico en sus protestas contra la precariedad laboral. Para ello, describimos tres experiencias de protesta social que utilizaron el arte como herramienta política: 1) la "caravana contra la precarización" de CTP entre 2006-2008, 2) el "limonadazo" de JCP en 2008 y, 3) las "bicicleteadas contra la precarización" de la Fragua en 2008. Estas experiencias las reconstruimos a partir de los sentidos de sus propios actores, analizando discursivamente sus posicionamientos subjetivos-colectivos. Recuperando nuestra hipótesis de trabajo, consideramos que es la falta de acceso a la representación sindical $\mathrm{y}$, por tanto, de sus repertorios de acción formales y protegidos jurídicamente, lo que conduce a los jóvenes precarizados a buscar canales alternativos de protesta, como el activismo artístico, que otorguen visibilidad a sus demandas.

\section{CTP, caravanas contra la precarización laboral (2006-2008)}

La Coordinadora de Trabajadores Precarizados (CTP), resultó un espacio de articulación de trabajadores precarizados de diferentes lugares laborales (call centers, ministerios, universidades, institutos) de la ciudad de Buenos Aires, que desarrolló sus actividades entre 2006 y 2008. Su origen estaba ligado a la Universidad de Buenos Aires (UBA), donde la mayoría de sus integrantes eran estudiantes y cuyas aulas utilizaban como espacio de reunión. La coordinadora aspiraba a ser un espacio de reflexión y denuncia sobre la precarización laboral, nucleando a estudiantes, trabajadores y organizaciones de diferentes espacios de trabajo. Así, frente a la segmentación de las formas contractuales, condiciones salariales, insatisfacciones y demandas, la CTP se definía como un espacio de resistencia al articularlas bajo un mismo frente contra la precarización compartida.

Nos parece importante, en primer lugar, reconocer la situación de precariedad en la que laboramos día a día. Tomar la sensación de enojo que nos recorre y convertirla en organización, 
salir de la queja para crear formas de resistencia que nos permitan modificar las condiciones de vida. Dejar de ver nuestra condición como individual y aislada y sabernos parte de una situación que nos afecta a la mayoría: a nuestros compañeros de facultad, a los que laboran en el mismo lugar que nosotros, a nuestros amigos y a los amigos de ellos. La Coordinadora de Trabajadores Precarizados surge como una alternativa para superar ese aislamiento, como un espacio de encuentro entre distintos grupos que veníamos planteando el problema de la precariedad y organizándonos a partir de ello (Boletín de CTP, $\left.\mathrm{N}^{\circ} 1,2007\right)$.

Además de la condición precaria, y como efecto de ella, sus integrantes compartían la ausencia de representación sindical para canalizar sus demandas como trabajadores, lo que los impulsaba a la autoorganización. Pero esa falta de acceso a la representación sindical, se encontraba atravesada por dos situaciones laborales distintas: en primer lugar, una amplia mayoría de los integrantes de la coordinadora eran trabajadores informales, que no contaban con una relación contractual registrada y por tanto se encontraban excluidos de la posibilidad de afiliarse a un sindicato. En segundo lugar, dentro de la coordinadora había también -aunque en menor medida- trabajadores formales, con contratos registrados y protecciones sociales, que si bien contaban con acceso a la representación sindical, no se sentían representados por el sindicato de su lugar de trabajo.

De esta manera, observamos que no solo la condición de precariedad contractual priva a los trabajadores de la representación sindical, sino que esta también se produce ante la falta de representatividad de los sindicatos. En la CTP, esta última situación se observa particularmente en el caso de los telemarketers que trabajaban en call centers, bajo contratos asalariados, estables y con acceso a beneficios sociales, pero desprotegidos ante la falta de condiciones físicas y ambientales de trabajo y con ausencia de regulación respecto al ritmo de trabajo. Estas problemáticas no eran tomadas en cuenta por el Sindicato de los Empleados de Comercio, que representaba formalmente a los trabajadores del sector.
Elegimos esta forma de organización para vencer los obstáculos que encon- tramos en nuestros espacios de trabajo para organizarnos y para enfrentar la exclusión a la que nos someten los sin- dicatos burocratizados, donde deciden unos pocos a espaldas de los trabajado- res (Boletín de CTP, $\mathrm{N}^{\circ}$ 1, 2007).

Esta situación nos conduce como investigadores a adoptar una perspectiva ampliada respecto a la precarización, observándola no solo en las condiciones contractuales, sino también en las condiciones materiales de trabajo, la subjetividad de los trabajadores y en las relaciones laborales de representación colectiva. En este sentido, apoyados en la perspectiva neomarxista francesa de la sociología del trabajo (Béroud y Bouffartigue, 2009), definimos a la precarización laboral como una materialización de la ofensiva del capital sobre el trabajo, que se despliega como un proceso desprotegiendo y fragmentando contratos, insatisfacciones y formas de representación colectiva, que debilitan la organización de los trabajadores. 
Dentro de la CTP, además de los telemarketers, participaban trabajadores de otros sectores como docentes de universidades e institutos, pasantes y empleados públicos contratados en ministerios estatales, que contaban con otras problemáticas referidas a las particularidades de su sector. Así, si bien todos compartían su posicionamiento como precarizados, la diversidad de sus lugares laborales se expresaba en la fragmentación de demandas, dificultando una articulación concreta. Esto incidía en que la coordinadora se transformara en un espacio de organización virtual, en el sentido que no tenía una práctica concreta en los espacios de trabajo, sino que actuaba como espacio de encuentro y apoyo en relación a la precarización laboral, en términos generales. En sintonía con ello, el principal repertorio de lucha de la CTP era la realización de grandes movilizaciones, conocidas como caravanas contra la precarización, cada 30 de abril (bautizada esta fecha por ellos como el día del trabajador precario).

Estas movilizaciones consistían en largas caravanas realizadas por las calles céntricas de Buenos Aires, con detenciones en las puertas de espacios laborales a los que denunciaban como precarizadores (consultoras, encuestadoras, ministerios, institutos de educación). En cada parada, los manifestantes representaban artísticamente situaciones de precarización utilizando disfraces, caretas, imágenes y hasta carrozas. Estas acciones asumían la forma de escrache en donde se aspiraba a visibilizar a los espacios laborales y al propio Gobierno como responsables de la precarización. Al igual que los escraches de H.I.J.O.S. en los noventa, la CTP desarrollaba esta manifestación ante la problemática laboral, desde un tono festivo y colorido, que aparecía en sí mismo como una actitud de rebeldía ante el propio mecanismo disciplinador que la precariedad genera sobre los cuerpos de los trabajadores.

La logística de las caravanas y la elección de sus herramientas artísticas de protesta, eran producto de las asambleas realizadas por la coordinadora antes de cada evento. Allí se decidían los lugares de escraches, se distribuían los roles y se organizaban comisiones para gestionar los diferentes elementos necesarios. Si bien la CTP tenía vinculación con el colectivo de artistas "Brazo Largo", la creación y la puesta en práctica del despliegue artístico en sus manifestaciones eran realizadas por los propios integrantes de la coordinadora, que no tenían formación artística. La mayoría de ellos atribuye a estas prácticas un carácter lúdico y de disfrute, y señalan su inspiración en los movimientos autonomistas españoles del 2000.

“¿Tenían algún modelo que tomaban de alguna organización?"

No lo sé, yo calculo que sí, porque Nico (un integrante fundacional de la CTP) se fue a vivir a España y ahí el movimiento de precarizados fue fuerte. Además, toda esta gente que se le ocurrió hacer la coordinadora habría leído mucho en la facultad sobre el movimiento de precarizados en Europa y después derivó en esto. Una vez Nico me dijo: "che, hay que venirse vestida como si fueras una gerente de call center". Y a mí todo lo que es actuación, vos avisame y yo voy, no tengo ningún problema (entrevista realizada a Maira, integrante de la CTP, 2015). 
Si bien la coordinadora duró solo dos años, generó una importante repercusión entre otros colectivos de precarios, que la tomaban de referencia, fundamentalmente en relación a sus emblemáticas caravanas. Respecto al final de la CTP en 2008, Arias y Crivelli (2010) identifican como principales motivos, en primer lugar, la propia condición de inestabilidad y rotación laboral de los trabajadores que repercutía en la inestabilidad de la militancia; y en segundo lugar, la doble identidad como estudiantes-trabajadores de sus integrantes, que resultaba problemática al interior del grupo, por los diferentes intereses y urgencias de quienes se posicionaban en cada uno de estos polos identitarios. De esta manera, la coordinadora se entendía de diversas maneras entre aquellos estudiantes que encontraban en ella un espacio político para luchar contra la precarización como problemática social, y aquellos trabajadores que buscaban en la organización una herramienta gremial para la transformación de sus problemáticas laborales concretas, que no terminaba de hacerse efectiva.

Terminamos porque ya está, porque tenemos crisis en todos los lugares de trabajo pero no logramos organizarnos, entonces no tiene sentido construir algo mayor (entrevista realizada a Ana, integrante de la CTP, 2015).

\section{JCP, limonadazo contra la precarización de los becarios (2008)}

Jóvenes Científicos Precarizados (JCP) es una agrupación gremial, de carácter informal, constituida por becarios de investigación de diferentes organismos científicos de la Argentina. Nació en 2005, en Buenos Aires, en una reunión de becarios que buscaban mejorar sus condiciones salariales y luego incorporó el reclamo por la inclusión de derechos laborales a sus contratos formativos. También se extendió geográficamente, añadiendo filiales en otras ciudades como La Plata, Tucumán, Córdoba y Rosario. En este trabajo nos centraremos en el caso de la filial fundacional, Buenos Aires.

El principal reclamo de JCP como organización gremial, que aún se mantiene como eje central de su lucha, es el reconocimiento del carácter laboral -además de formativo- de sus contratos, lo cual resulta ser la condición fundamental para acceder a beneficios sociales como aportes jubilatorios, licencias, indemnizaciones y asignaciones familiares, entre otras. En sus 12 años de lucha, la organización fue variando en sus integrantes, que finalizaban sus becas, cambiaban de trabajo o ingresaban a la planta estable de sus organismos de trabajo. Pero a pesar de esta rotación, JCP siempre se mantuvo activo y con una estructura de organización horizontal y autónoma. Durante este período, si bien lograron algunas conquistas como la incorporación de algunos derechos laborales (licencias por maternidad y obra social), aún permanece pendiente el reconocimiento laboral de sus contratos.

En términos de relaciones laborales sindicales, si bien al igual que la CTP se posicionan como una autoorganización de carácter independiente, tienen una mayor relación con los sindicatos. Puntualmente, en los últimos cinco años JCP estableció un vínculo cercano con el sindicato Asociación de Trabajadores del Estado (ATE). Este sindicato, pertenece a la Central de Trabajadores de la Argentina (CTA), que tiene una concepción 
ampliada de sus representados, incluyendo a trabajadores informales y precarios. Sin embargo, y a pesar de realizar actividades y participar de manifestaciones junto al sindicato, JCP se mantiene como una agrupación autónoma y alternativa. Justifican ese posicionamiento en el carácter independiente que define a la agrupación y en la defensa del carácter particular del reclamo de los becarios.

En la primera etapa de JCP (2005-2009), este rasgo autonomista era más fuerte; incluso el propio nombre de la agrupación y el color amarillo que la identifica surgió inspirado en el movimiento autonomista de científicos precarizados de España, llamados "los precarios".

Mucho de lo que tomamos fue de la lucha de los españoles, que estaban ahí en plena pelea por lo mismo, por el reconocimiento de trabajadores. Eran jóvenes científicos de allá. Ellos se llamaban "precarios", esa era su organización. Se llamaban los precarios, usaban unas remeras naranjas, hacían unas grandes movilizaciones todos vestidos de naranja. Hicieron mucha movilización y consiguieron que los contraten (entrevista realizada a Esteban, integrante de JCP, 2014).

Svampa (2011) señala una vinculación entra las organizaciones autonomistas juveniles y el activismo artístico, a través del desarrollo de prácticas que suelen adoptar una dimensión política y a la vez cultural. Respecto a estas prácticas, JCP realizó -fundamentalmente en sus primeros años- diferentes intervenciones artísticas en la vía pública, como un partido de fútbol en una avenida céntrica de Buenos Aires bajo el lema: "que no te golee la inflación" (en el marco del Mundial de Fútbol Alemania 2006), el reparto de chocolate caliente vestidos con guardapolvos en las puertas del Ministerio de Ciencia y Tecnología, y el emblemático "limonadazo" contra la precarización -la "exprimida", decían- de los becarios por parte del sistema científico. Esta actividad se realizó durante la fiesta del 50 aniversario del Consejo Nacional de Investigaciones Científicas y Técnicas (Conicet) en 2008, y consistió en que los miembros de JCP -con sus remeras amarillas identificatorias- entregaban limonadas con panfletos de denuncia a los asistentes.

Mientras el auditorio de la Facultad de Derecho comenzaba a poblarse de científicos y funcionarios de turno vestidos para la celebración de los 50 años del Conicet, en las escalinatas del exterior reinaba el amarillo: el de las remeras, las banderas, las pancartas y los limones exprimidos por los Jóvenes Científicos Precarizados, una organización que agrupa a 850 becarios en todo el país, que se movilizaron realizando un "limonadazo" para simbolizar cómo son exprimidos por el sistema científico nacional (Diario Crítica, 14 de abril de 2008).

JCP no contaba con vínculos con ningún colectivo de artistas ni tampoco con alguno de ellos entre sus integrantes. Se trataba de una agrupación gremial formada exclusivamente por becarios de investigación que estaban realizando carreras de posgrado. Pero la participación en otras movilizaciones de precarios, como las caravanas de la $\mathrm{CTP}$, en donde resultaba frecuente el uso de herramientas artísticas, actuó como un 
dispensario de repertorios de activismo artístico que JCP aplicaba en sus propias movilizaciones. En cierta manera, esas participaciones fueron espacios de socialización para los integrantes de JCP sobre este tipo de herramientas no convencionales de acción colectiva, fundamentalmente en la primera etapa del decenio, en donde había un clima de continuidad con la efervescencia de protesta social del año 2001 en el que el "activismo artístico" se encontraba legitimado como recurso de visibilidad de las protestas.

Progresivamente, observamos que el uso del repertorio de acción artístico comenzó a decrecer en JCP, al compás de su vinculación con el sindicato ATE y de su participación en instancias de negociación formal con las autoridades del Ministerio de Ciencia y Tecnología. En otro trabajo académico (Adamini, 2016) mostramos cómo el incremento en la formalización de las organizaciones sindicales informales se da de forma paulatina al incremento de su contacto con organizaciones sindicales tradicionales. Agregamos ahora que a partir de este contacto, también se produce una mutación en los repertorios de acción, en donde aquellos más alternativos -como el activismo artístico- van perdiendo centralidad ante la participación en instancias de protesta y negociación tradicionales junto a los sindicatos.

\section{La Fragua, bicicleteadas contra la precarización (2008)}

La Fragua surgió en 2006 como el espacio de organización de los trabajadores del movimiento social Frente Popular Darío Santillán (FPDS) en la ciudad de La Plata ${ }^{7}$, buscando denunciar las formas laborales precarias en el empleo público (Bouffartigue y Busso, 2010), en términos contractuales, salariales y de condiciones materiales de trabajo. Esta agrupación está compuesta fundamentalmente por trabajadores que desarrollan tareas laborales como docentes y empleados estatales, muchos de los cuales cuentan con contratos precarios, pero también -al igual que en la CTP- hay empleados formales que no se sienten representados por los sindicatos de su lugar de trabajo.

Sus primeras actividades como organización, consistieron en la realización de charlas de discusión sobre condiciones laborales, jornadas de debate en universidades (donde la mayoría de sus integrantes eran estudiantes), la publicación de un boletín de difusión de las mismas -llamado "La Fragua"- y actividades de propaganda (afiches, volanteadas, radios abiertas) como medio de difusión y denuncia de la precarización laboral, en términos generales. Recién un año después de su creación, con la propia consolidación institucional de la organización, comenzaron a involucrarse en acciones colectivas en los lugares laborales de sus integrantes, a partir del desarrollo de movilizaciones y cortes de calle. Entre ellas, resultaron significativas las jornadas de lucha realizadas frente al despido de trabajadores municipales de la ciudad de La Plata en 2007. Además, La Fragua inició en ese mismo período procesos de articulación con otras agrupaciones de precarizados, como la CTP y JCP, participando en sus movilizaciones.

organizaciones sociales de estudiantes, trabajadores, desocupados, artistas e intelectuales, entre otros. 
La particularidad de La Fragua como colectivo, a diferencia de las otras dos agrupaciones mencionadas, es su inscripción en un movimiento social más amplio como es el FPDS. Esto los inserta en las propias prácticas políticas del espacio, y también les permite una articulación con otros grupos del movimiento, ajenos al campo gremial. De forma puntual, y a la luz del objetivo de este trabajo, podemos observar la incidencia que tiene el arte en sus jornadas de lucha a partir del vínculo que establecen con la rama de artistas activistas del movimiento llamada Arte al Ataque.

Esta rama artística del FPDS surgió en 2008, buscando impulsar actividades culturales y articulándose con los diferentes grupos que componen el movimiento, entre ellos el gremial. Sus fundadores definen como su objetivo:

Generar dentro del movimiento la estetización de la política y la politización del arte como formas fundamentales para poder llevar adelante el cambio social, relación compleja, pero fundamental para poder desarrollar nuevas relaciones sociales a través del cambio en el lenguaje, y la disputa ideológica y simbólica a través de la manifestación artística como la forma de considerar la transformación social de manera cotidiana (Aprea, Alainez y Landi, 2009, p. 5).

Una de las intervenciones conjuntas de La Fragua y Arte al Ataque, fue la realización de las "bicicleteadas contra la precarización" en la ciudad de La Plata durante 2008. Estas consistieron en largas caravanas de bicicletas, conducidas por jóvenes disfrazados con caretas de playmovil, que con banderas y bocinas llamaban la atención de los transeúntes en las calles céntricas de La Plata. Lo crucial de estas caravanas eran los puntos de detención, que consistían en espacios laborales a los que denunciaban como "precarizadores". Entre ellos, se encontraban empresas como la empresa multinacional de comidas McDonald's, el supermercado nacional COTO y la constructora local Building, e instituciones como la Universidad Nacional de La Plata y el Ministerio de Trabajo de la Provincia de Buenos Aires. “En cada punto se realizaba una performance o breve representación teatral de situaciones de precarización, explotación y maltrato laboral, además de denunciar (mediante estadísticas y datos) a las empresas y al estado municipal" (Pérez Balbi, 2014, p. 8).

Uno de los integrantes de La Fragua rememora de esta manera la experiencia de la bicicleteadas:

No solo eran bicicleteadas donde íbamos a visitar cada uno de los puntos donde nosotros queríamos escrachar, sino que también eran producciones artísticas, porque había compañeras y compañeros que se ponían a actuar. Estaba el payaso Ronald McDonald precarizado, que nos moríamos de risa. También empleados estatales que se disfrazaban o trabajadores de la construcción y ahí íbamos pasando por distintos lugares.

“¿Qué buscaban con eso?”

Visibilizar la cuestión de la precarización en ciertos lugares donde nosotros teníamos actividad sindical o creíamos que eran hitos de esa precarización, porque en McDonald's no teníamos ningún laborante pero sin embargo 
nos parecía un lugar interesante para ir a pegarle (entrevista realizada a Antonio, integrante de La Fragua, 2015).

De modo similar a las "caravanas contra la precarización" de la CTP, el despliegue artístico en las bicicleteadas lograba cumplir el objetivo de visibilizar la denuncia de La Fragua sobre el carácter precarizador de ciertos lugares laborales, que eran "escrachados" a partir de actuaciones, cánticos y carteles. Otro rasgo compartido con las intervenciones de precarizados anteriormente analizada, es que estas prácticas de denuncia se daban en un clima lúdico y de disfrute habilitado por sus expresiones artísticas. De esta manera, se recuperaba el espíritu del escrache inaugurado por H.I.J.O.S., donde la denuncia sobre una problemática (de violación de derechos humanos en ese caso, precarización laboral en este) se enmarca en un clima festivo y de alegría, que actúa en sí mismo un posicionamiento subjetivo-colectivo de resistencia frente al daño generado por los escrachados.

En sus 12 años de recorrido, La Fragua fue consolidándose como organización gremial, desarrollando prácticas autónomas al FPDS y estableciendo canales de articulación con organizaciones sindicales formales, como el sindicato de docentes estatales SUTEBA, que al igual que ATE pertenece a la CTA. Incluso, algunos de los integrantes de $\mathrm{La}$ Fragua disputaron el rol de representantes sindicales en comisiones internas y cuerpos de delegados en sus lugares de trabajo. Esta disputa, se realizaba desde listas alternativas que cuestionaban el carácter burocratizado y negociante de los sindicatos tradicionales y proponían una nueva forma de representación, horizontal y democrática.
Este acercamiento de La Fragua al sindicalismo formal, generó un paulatino abandono de los mecanismos alternativos de protesta, como las movilizaciones artísticas, junto a un fortalecimiento de mecanismos tradicionales de disputa como la participación en listas sindicales, en instancias de negociación con empleadores y la realización de paros de actividades. En sintonía con ello, se produjo un pasaje de las denuncias generales sobre la precarización a la disputa de problemáticas laborales concretas en los lugares de trabajo, que fortaleció su reconocimiento como representante gremial por parte de empleadores y de trabajadores ajenos al movimiento social al que pertenecían.

\section{REFLEXIONES FINALES}

El objetivo de nuestro artículo, fue analizar el rol del activismo artístico como herramienta de lucha de organizaciones de jóvenes trabajadores precarizados en Argentina. Realizamos para ello, un estudio de caso comparativo entre las organizaciones CTP, JCP y La Fragua, las cuales recurrieron al activismo artístico en sus movilizaciones a partir del uso de disfraces, carteles, actuaciones y canciones. Más allá de las particularidades de cada una, todas compartían la aspiración de dar visibilidad a sus demandas con este recurso. En función a ello, nuestra hipótesis de trabajo inicial sostenía que el carácter precario de sus trabajos excluía a estos trabajadores de los canales sindicales formales de negociación y protesta, y por ese motivo, recurrían al activismo artístico como estrategia alternativa para instaurar sus reclamos en el espacio público.

El propio desarrollo de nuestro trabajo de investigación y análisis nos condujo a 
complejizar esta hipótesis. Observamos así, que si bien, la condición contractual precarizada es la principal razón que excluye a los trabajadores del derecho a la afiliación sindical y los conduce a la búsqueda de canales alternativos de organización y acción colectiva, no es la única circunstancia que incide en ello. A partir del estudio cualitativo realizado, encontramos que en la CTP y La Fragua participan, además, trabajadores formales, quienes cuentan con contratos laborales registrados y derecho a afiliación sindical pero no se sienten representados por sus representantes. El activismo artístico les permite así obtener visibilidad para posicionarse en el espacio público y plantear sus reclamos acerca de las condiciones precarias de sus trabajos.

Por otro lado, observamos que el uso del activismo artístico como repertorio terminó siendo una práctica temporal para las organizaciones de jóvenes precarios en estudio. Si bien, esta resultó asidua en sus primeras etapas -como herramienta para darse visibilidad-, progresivamente se dio un paulatino abandono de ella en sintonía con el incremento en el uso de los canales sindicales tradicionales de lucha. Incidieron en ello distintos factores: en primer lugar, su consolidación como organizaciones gremiales, habilitó un mayor acercamiento con los sindicatos formales, que las incluyeron en sus prácticas de negociación y de lucha. En segundo lugar, en sintonía con este proceso de consolidación gremial, las organizaciones terminaron buscando soluciones concretas para las problemáticas de precarización laboral de sus lugares laborales, donde resultaban más efectivas las herramientas sindicales tradicionales (como las negociaciones y los paros). En tercer lugar, la recuperación de la estabilidad política a partir del Gobierno kirchnerista, generó un desaliento en el uso de repertorios de acción autonomistas -propios de la protesta social del 2001- y promovió canales institucionales de negociación, que revitalizaron al sindicalismo tradicional.

Pero esta conclusión, más que aspirar a mostrar las limitaciones del activismo artístico como repertorio de acción de los precarizados, busca comprender sus condiciones de emergencia, de aplicación y también su sentido en términos históricos. Consideramos que a pesar de su carácter transitorio como recurso de lucha en las organizaciones en estudio, resultó valiosa en su proceso de constitución organizacional, dándoles visibilidad como nuevas organizaciones gremiales y posicionando en el espacio público la problemática de la precariedad laboral. Por otro lado, más allá de la centralidad y efectividad que mantienen las herramientas sindicales tradicionales, la emergencia del activismo artístico como repertorio gremial, implica en sí mismo un proceso de renovación sobre las formas de lucha de los trabajadores, que nos advierte sobre la necesidad de ampliación de sus repertorios de acción -y también de las miradas sobre ellos- en un mundo laboral en permanente transformación.

\section{REFERENCIAS}

Abal Medina, P. (2014). Ser solo un número más. Trabajadores jóvenes, grandes empresas y activismos sindicales en la Argentina actual. Buenos Aires, Argentina: Biblos.

Adamini, M. (2015). Reflexiones sobre la emergencia de 'nuevas formas de organización no sindical' en el marco de 
revitalización del conflicto laboral durante la Argentina posneoliberal (20032015). Ponencia llevada a cabo en el $12^{\circ}$ Congreso Nacional de Estudios del Trabajo de la Asociación Argentina de Especialistas en Estudios del Trabajo, Buenos Aires, Argentina.

Adamini, M. (2016). Reacciones colectivas de jóvenes precarios en la era kirchnerista: un estudio sobre organizaciones sindicales informales en Buenos Aires y La Plata. Ponencia llevada a cabo en el IV Encuentro Internacional de Teoría y Práctica Política en América Latina. Universidad Nacional de Mar del Plata, Mar del Plata, Argentina.

Almazán, Y. A., y Clavo, M. I. (2007). Arte, política y activismo. Concinnitas, 1(8), 65-77. Recuperado de file://C:/Users/ Usuario/Downloads/22888-73767-1-PB. pdf

Antunes, R. (1999). ¿Adiós al trabajo? Ensayo sobre las metamorfosis y el rol central del mundo del trabajo. Buenos Aires, Argentina: Editorial Antídoto.

Aprea, M., Alainez, C., y Landi, M. (2009). Arte al ataque: agitando cultura para el cambio social desde y con otras organizaciones políticas-culturales. Ponencia llevada a cabo en el 1er. Congreso Nacional sobre Protesta Social, Acción Colectiva y Movimientos Sociales, Quilmes, Argentina.

Arias, C. C., y Crivelli, K. (2010). Ensayando prácticas de articulación colectiva: la Coordinadora de Trabajadores Precarizados de la Ciudad de Buenos Aires. Ciências Sociais Unisinos, 46(1). Recuperado de http://www.redalyc.org/ html/938/93820632011/

Bauman, Z. (2005). Identidad. Buenos Aires, Argentina: Losada.
Benveniste, E. (1974). Problemas de lingüística general II. Madrid, España: Siglo Veintiuno Editores.

Béroud, S., y Bouffartigue, P. (Dir.) (2009). Quand le travail se précarise, quelles résistances collectives? París, Francia: La Dispute.

Bouffartigue, P., y Busso, M. (2010). Precariedad, informalidad: una perspectiva "Norte-Sur" para pensar las dinámicas del mundo del trabajo. Ponencia llevada a cabo en VI Congreso de ALAST, México.

Bourdieu, P. (1998). Contrafuegos. Reflexiones para servir a la resistencia contra la invasión neoliberal. Barcelona, España: Editorial Anagrama.

Boyer, R. (1978). Les salaires en longue periode. Economie et Statistique, 103(1), 27-57. Recuperado de http:// www.persee.fr/doc/estat_0336-1454 _1978_num_103_1_3028

Bruno, D. (2012). Artivismo y espacio público en la praxis de Arte al Ataque en el Frente Popular Darío Santillán. AVATARES de la Comunicación y la Cultura, (4), 113. Recuperado de http://ppct.caicyt.gov.ar/index.php/avatares/article/ viewFile/2503/2362

Delgado, M. (2013). Artivismo y pospolítica. Sobre la estetización de las luchas sociales en contextos urbanos. Quaderns-e del InstitutCatalàd'Antropologia, 2(18), 6880. Recuperado de https://www.raco. cat/index.php/QuadernseICA/article/ viewFile/274290/362359

De la Garza Toledo, E. (2010). Hacia un concepto ampliado de trabajo. Barcelona, España: Anthropos.

Dubar, C. (2000). La socialisation: construcción de identités sociales et profesionelles. París, Francia: Armand Colin. 
Etchemendy, S., y Collier, R. B. (2007). Down but not out: Union resurgence and segmented neocorporatism in Argentina (2003-2007). Politics \& Society, 35(3), 363-401. Recuperado de http://www.rochelleterman.com/ComparativeExam/ sites/default/files/Bibliography $\% 20$ and $\% 20$ Summaries/Etchemendy $\% 20$ \%20Collier\%20\%202007.pdf

Felshin, N. (2001). ¿Pero esto es arte? El espíritu del arte como activismo. En $\mathrm{P}$. Blanco, J. Carrillo, J. Claramonte, y M. Expósito (Eds.), Modos de hacer. Arte crítico, esfera pública y acción directa (pp. 73-94). Salamanca, España: Ediciones Universidad de Salamanca.

Giménez, G. (1996). Territorio y cultura. Estudios sobre las culturas contemporáneas. Época II, 2(4), 9-30. Recuperado de http://www.redalyc.org/ html/316/31600402/

Gorz, A. (1997). Metamorfosis del trabajo. Madrid, España: Editorial Sistema.

Longoni, A. (2009). Activismo artístico en la última década en Argentina. En $P a-$ nel Re-conocimientos: identidad, referentes culturales, nuevos movimientos sociales $y$ responsabilidad del intelectual. Intervención realizada en Casa Tomada, Cuba. Recuperado de http://www.rebelion. org/noticia.php?\%20id=97449

Mannheim, K. (1928/1993). El problema de las generaciones. Revista Española de Investigaciones Sociológicas, 62, 193-242. Recuperado de file://C:/Users/Usuario/ Downloads/Dialnet-ElProblemaDeLasGeneraciones-766796.pdf

Mazur, J. (2000). Labor's New Internationalism. Foreign Affairs, 79(1), 19-93. Recuperado de https://gse.uml.edu/atah/ pdf/ForrantSeattle.pdf
Moody, K. (1997). Towards and International Social Movement Unionism. New Left Review, 1(225), 52.

Offe, C. (1985). Disorganiced Capitalism. Contemporany transformations of Work and Politics. Cambridge, UK: Polity Press.

Pérez Balbi, M. (2012). Desbordes y convergencias: la dimensión de lo público en el activismo artístico actual en la Argentina. Question, 1(35), 140-153. Recuperado de http://sedici.unlp.edu.ar/bitstream/ handle/10915/35152/Documento_completo.pdf?sequence $=1$

Pérez Balbi, M. (2014). Sobre los puntos suspensivos. Una breve discusión terminológica sobre prácticas de activismo artístico. Ponencia llevada a cabo en VIII Jornadas de Sociología de la UNLP, La Plata, Argentina.

Rifkin, J. (1996). El fin del trabajo. México D. F., México: Paidós.

Seidman, G. (1994) Manufacturing Militance. Berkeley, CA: University of California Press.

Senén González, C., y Del Bono, A. (2013). Introducción. En Senén González, C., La revitalizacion sindical en Argentina y sus heterogeneidades culturales. Buenos $\mathrm{Ai}-$ res, Argentina: Prometeo, 7-22.

Senén González, C., y Haidar, J. (2009). Los debates acerca de la "revitalización sindical" y su aplicación en el análisis sectorial en Argentina. Revista Latinoamericana de Estudios del Trabajo, (22), 5-31. Recuperado de file://C:/Users/Usuario/Downloads/190-1-299-1-10-20171016.pdf

Sennett, R. (2000). La corrosión del carácter. Las consecuencias personales del trabajo en el nuevo capitalismo. Barcelona, España: Anagrama. 
Silver, B. (2005). Fuerzas de trabajo. Los movimientos obreros y la globalización desde 1870. Madrid, España: Ediciones Akal.

Stake, R. (1994). Case Study. En Denzin, N.K., y Lincoln, Y.S. (Eds.) Handbook of Qualitative Research. London: Sage.

Svampa, M. (2010). Movimientos sociales, matrices sociopolíticas y nuevos escenarios en América Latina. One World Perspectives, Workings Papers (1).

Svampa, M. (2011). Argentina, una década después del "que se vayan todos" a la exacerbación de lo nacional-popular. Nueva Sociedad, (235), 17-34. Recuperado de http://maristellasvampa.net/archivos/ensayo55.pdf

Varela, P. (2009). ¿De dónde salieron estos pibes? Consideraciones sobre el activismo gremial de base en Argentina posdevaluación. Margen: Revista de trabajo social y ciencias sociales, (55). Recuperado de https://www.margen.org/ suscri/margen55/varela.pdf

Vasilachis de Gialdino, I. (2008). Los fundamentos epistemológicos de la investigación cualitativa. En Cohen, N., y Piovani, I. (Comp.) La metodología de la investigación en debate. Buenos Aires, Argentina: Eudeba- Ed. UNLP.

Visser, J. (1991). La representación de los trabajadores en los centros de trabajo en Europa Occidental: Estructura, escala, alcance y estrategia. Sociología del Trabajo, (14), 3-44. 